\title{
XXXIII Congreso Chileno de Obstetricia y Ginecología. El Congreso de la salud integral de la mujer
}

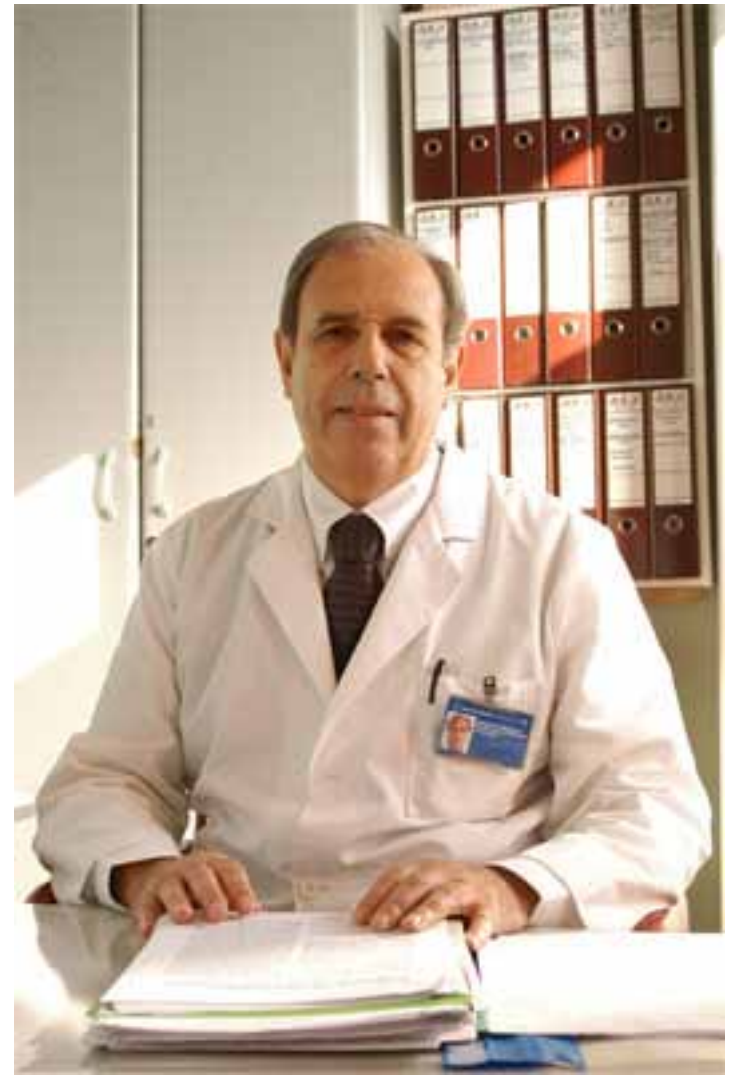

Junto con enriquecer los conocimientos, la educación continua permite mejorar nuestra competitividad en un escenario que es cada vez más exigente. En ese contexto, la participación en un congreso médico es, sin duda, una oportunidad valiosa para actualizarnos, compartir experiencias con los colegas y estrechar nuestras redes de contacto.

Conscientes de esta importancia y de los desafíos que hoy exige la medicina y en particular nuestra especialidad, hemos puesto todo nuestro esfuerzo en organizar el XXXIII Congreso Chileno de Obstetricia y Ginecología, el cual se realizará en Viña del Mar los días 13, 14 y 15 de noviembre de 2011.

Este esfuerzo se ha visto reflejado en la calidad del programa, de los invitados y especialmente en la energía que hemos invertido para integrar de manera concreta a todas las Sociedades afines a la Sociedad Chilena de Obstetricia y Ginecología (SOCHOG). Tal como lo hemos hecho en otras instancias (como las reuniones clínicas por ejemplo), nuestro principal desafío como sociedad científica es lograr aglutinar el quehacer de todas las Sociedades afines, y en ese sentido hemos invitado a cada una de ellas a participar de forma activa en el programa científico de nuestro congreso. Por ello, el congreso de la SOCHOG se convierte en una instancia única donde se abarcarán todos los temas que atañen a la salud de la mujer.

Por otro lado, aprovechando nuestras redes de contacto que hemos forjado a nivel nacional e internacional, el programa incluirá la participación de expositores provenientes de los más importantes organismos de la gineco-obstetricia. Chile a través de la SOCHOG, se ha convertido en un referente a la hora de realizar nexos con los diversos organismos internacionales de la especialidad, los cuales deseamos que se vean reflejados en este congreso. En ese sentido, cabe destacar la excelente relación que la SOCHOG mantiene con el American College of Obstetrician and Gynecologists (ACOG) y que se ve reflejada a través del Capítulo Chileno de ACOG, que a la fecha cuenta con alrededor de 100 gineco-obstetras fellows y 50 junior fellows.

A nivel nacional, nuestra participación tampoco ha sido menor. Dentro del espíritu de cumplir una función país, miembros de la SOCHOG han ejercido puestos claves en el Ministerio de Salud (MIN$S A L)$, y han integrado comisiones de trabajo en la formación de guías clínicas y protocolos, además de su aporte en el ámbito de las políticas públicas. 
Particularmente hoy, la SOCHOG está trabajando en la definición de los objetivos sanitarios en la salud de la mujer.

Asimismo, este año acabamos de recibir de parte del MINSAL el decreto que aprobó la creación de la "Comisión Nacional Obstétrica Neonatal", que cuenta con un número importante de médicos de la SOCHOG y cuyo objetivo es asesorar al MINSAL en la promoción y fortalecimiento de la salud de la mujer embarazada y del recién nacido, a fin de disminuir la morbimortalidad materna y perinatal.

Todos los temas involucrados a estos importantes hechos, los vamos a integrar en el programa del congreso de la SOCHOG y con ello permitir el per- feccionamiento académico de nuestros especialistas y por lo tanto, seguir manteniendo los principios que inspiraron a aquellos médicos que fundaron la SOCHOG hace 75 años, quienes soñaron con hacer del ejercicio de la gineco-obstetricia una disciplina en constante crecimiento.

Los dejamos a todos cordialmente invitados al congreso. Los esperamos en Noviembre en Viña del Mar.

Saludos afectuosos, Dr. Luis Martínez M.

Presidente.

Sociedad Chilena de Obstetricia y Ginecología. 